\title{
Concentrate for Cutaneous Solution Dosage Form
}

National Cancer Institute

\section{Source}

National Cancer Institute. Concentrate for Cutaneous Solution Dosage Form. NCI

Thesaurus. Code C149384.

Liquid preparation intended to be diluted in the specified liquid to obtain a cutaneous solution. 